\title{
The long-term behaviour of one-way spanning slabs under variable loading
}

\author{
G. T. G. MOHAMEDBHAI \& R. TAYLOR
}

\section{Mr J. S. Marshall, James Carrington and Partners}

The unfortunate, though very demonstrative, accidental wetting shows the effect of moisture on the deflexion of the slabs. The rate of change of moisture content would appear to govern the rate of change of consequent defiexion. Sudden wetting gave rise to rapid reduction of deflexion, and slow drying due to evaporation gave rise to a slow return to normal.

56. Figure 2 gives a clear indication of the large proportion of the top surface necessarily covered to produce a uniformly distributed load.

57. As evaporation from the covered areas was either greatly restricted or rendered impossible, were the top surfaces of the control specimens covered to the same extent so as to allow evaporation at the same rate?

\section{Dr Mohamedbhai and Mr Taylor}

We agree with $\mathrm{Mr}$ Marshall that the rate of change of moisture determines the shrinkage strains and therefore the amount of shrinkage deflexion, but the ultimate shrinkage deflexion after drying is basically the same, irrespective of the rate at which drying takes place.

59. In reply to his question, the unloaded slabs S11 and S21 were not covered to simulate the covered portions of the loaded slabs. The loads did not actually cover the top surface of the slab as fully as it appears in Fig. 2. The 50\% loaded slab had $35 \%$ of its top surface covered, the $75 \%$ loaded slab $52 \%$ and the $100 \%$ loaded slab $69 \%$.

60. Thus, although we consider that the point raised is valid, we believe that the restricted evaporation of the top surface of the slabs did not substantially affect the shrinkage deflexions. The slabs were first loaded, and readings of strains and deflexions taken, 35 days after casting; at that age a large amount of shrinkage in the concrete must have already taken place.

Paper published: Proc. Instn. Civ. Engrs, Part 2, 1974, 57, Mar., 67-82. 